ISSN 0103-9954

\title{
ANÁLISE FITOSSOCIOLÓGICA E DO ESTOQUE DE CARBONO NO ESTRATO ARBÓREO DE UM FRAGMENTO DE FLORESTA ESTACIONAL SEMIDECIDUAL
}

\author{
PHYTOSOCIOLOGICAL AND CARBON STOCK ANALYSIS IN THE TREE LAYER OF A \\ SEMIDECIDUOUS FOREST FRAGMENT
}

\author{
Ricardo de Oliveira Gaspar ${ }^{1}$ Renato Vinícius Oliveira Castro ${ }^{2}$ Ricardo Vieira Del Peloso 3 \\ Felippe Coelho de Souza ${ }^{4}$ Sebastião Venâncio Martins ${ }^{5}$
}

\begin{abstract}
RESUMO
Os estudos direcionados para quantificação de estoques de carbono fixado por florestas naturais estão em ampla evidência, assim como a discussão sobre a efetividade da recuperação de áreas degradadas como estratégia para reduzir os níveis de $\mathrm{CO}_{2}$ atmosférico. Neste sentido, tiveram-se dois objetivos neste artigo: i) quantificar o estoque de carbono presente na biomassa da parte aérea de um fragmento de Floresta Estacional Semidecidual Montana, pertencente ao Bioma Mata Atlântica no estado de Minas Gerais e ii) incorporar a variável estoque de carbono na estrutura horizontal da análise fitossociológica e comparar os resultados aos obtidos pela metodologia padrão, sem utilizar essa variável no cálculo do valor de importâncias das espécies. Os resultados indicam que o estoque de carbono encontrado equivale a fragmentos em estágio médio de sucessão, e que a utilização da variável carbono influencia sobremaneira o valor de importância das espécies. Esta metodologia serve como suporte para a escolha de espécies arbóreas de maior potencial para sequestrar carbono e pode subsidiar programas de restauração de remanescentes florestais do Bioma de Mata Atlântica.
\end{abstract}

Palavras-chave: Mata Atlântica; estoque de carbono; sequestro de carbono; estrutura horizontal.

\begin{abstract}
The studies directed to quantify the carbon fixed stocks by natural forests are in ample evidence, as well as discussion about the effectiveness of the recovery of degraded areas as a strategy to reduce atmospheric $\mathrm{CO}_{2}$ levels. In this sense, this study had two purposes: i) quantify the carbon stocks present in the shoot biomass of a tropical semi-deciduous Montana fragment, which belongs to the Atlantic Forest biome in Minas Gerais state and; ii) incorporate the variable carbon stock in the horizontal phytosociological analysis structure and compare the results to those obtained by the standard methodology without using the variable in the calculation of the species importance value. The results indicate that the carbon stock equals to the fragments found at the intermediate succession stage, and that the carbon variable use greatly influences the species importance value. This methodology serves as a support for the selection of species which present the greatest potential to sequester carbon and may support programs for the remnant restoration of the Atlantic Forest biome.
\end{abstract}

Keywords: Atlantic Forest; carbon stock; carbon sequestration; horizontal structure.

1 Engenheiro Florestal, Dr., Professor do Departamento de Engenharia Florestal, Universidade de Brasília, CEP 70904-970, Brasília (DF), Brasil. ricogaspar.floresta@yahoo.com.br

2 Engenheiro Florestal, Dr., Professor do Departamento de Ciências Agrárias, Universidade Federal de São João del Rey, Campus Sete Lagoas, CEP 35701-970, Sete Lagoas (MG), Brasil. castrorvo@ymail.com

3 Engenheiro Florestal, Msc., Universidade Federal de Viçosa, CEP 36570-000, Viçosa (MG), Brasil. ricardopeloso@gmail.com

4 Engenheiro Florestal, Msc., Doutorando em Ciência Florestal, Universidade Federal de Viçosa, CEP 36570-000, Viçosa (MG), Brasil. felippeenf@yahoo.com.br

5 Engenheiro Florestal, Dr., Professor do Departamento de Engenharia Florestal, Universidade Federal de Viçosa, CEP 36570-000, Viçosa (MG), Brasil. venancioufv@gmail.com

Recebido para publicação em 2/09/2011 e aceito em 13/12/2012

Ci. Fl., v. 24, n. 2, abr.-jun., 2014 


\section{INTRODUÇÃO}

Com grande biodiversidade e endemismo, a Floresta Tropical Atlântica merece destaque entre as formações florestais brasileiras. Este Bioma se encontra restrito a pequenos fragmentos desprotegidos e altamente alterados, representando cerca de $12 \%$ da cobertura original (TABARELLI et al., 2005; RIBEIRO et al., 2009). Existe grande necessidade de se conservar estes remanescentes florestais, bem como implantar métodos de recuperação das áreas degradadas visando à restauração da biodiversidade, para que estes fragmentos possam novamente fornecer benefícios e serviços ambientais que são característicos de florestas bem preservadas (YOUNG, 2000; LAMB et al., 2005; CHAZDON, 2008).

A redução da extensão de florestas tropicais resulta em maiores emissões de carbono (C), o que contribui efetivamente para o aumento da concentração atmosférica de $\mathrm{CO}_{2}$. A redução destas áreas foi responsável por emitir nas últimas décadas uma média de 1,5 $\mathrm{Pg} \mathrm{C}_{\text {ano }}{ }^{-1}$, o que representa cerca de $24 \%$ das emissões globais que são provenientes da queima de combustíveis fósseis (HOUGHTON, 2005). Desta forma, um serviço ambiental fornecido pelas florestas tropicais tem recebido destaque atualmente: o de manutenção dos estoques de carbono (FEARNSIDE, 2006; FORSTER e MELO, 2007). Estudos recentes têm abordado a fixação de carbono em florestas nativas pertencentes ao Bioma Mata Atlântica (MELO e DURIGAN, 2006; CUNHA et al., 2009; RIBEIRO et al., 2010), visando avaliar o potencial destas florestas para redução de emissões de $\mathrm{C}$ com práticas de conservação dos fragmentos e restauração das áreas degradadas, corroborando para a inclusão destas em projetos de Mecanismos de Desenvolvimento Limpo (MDL).

Os programas de restauração dos remanescentes da Floresta Atlântica contribuem para a fixação de carbono (MONTAGNINI e PORRAS, 1998; SILVER et al., 2000; MELO e DURIGAN, 2006), além da recuperação da biodiversidade destes ambientes. Neste contexto, estudos fitossociológicos são imprescindíveis para fornecer diretrizes conceituais para a restauração florestal (MORELLATO e HADDAD, 2000). Com o conhecimento da estrutura e dinâmica do fragmento da Mata Atlântica que será restaurado pode-se atentar para a escolha de espécies florestais a serem utilizadas na recomposição. Para esta escolha, um critério interessante de se avaliar é a capacidade natural das espécies de sequestrar $\mathrm{CO}_{2}$ da atmosfera, por meio da fotossíntese, e fixá-lo sob a forma de carbono na matéria lenhosa, buscando assim, restaurar a floresta bem como estocar uma maior fração de carbono atmosférico.

Desse modo, este trabalho teve por objetivos: i) quantificar o estoque de carbono presente na biomassa da parte aérea de um fragmento de Floresta Estacional Semidecidual Montana, pertencente ao Bioma Mata Atlântica no estado de Minas Gerais e ii) incorporar a variável carbono no cálculo do valor de importância (VI) das espécies na estrutura horizontal e comparar os resultados aos obtidos pela metodologia padrão, sem utilizar a variável carbono no cálculo do VI das espécies.

\section{MATERIAL E MÉTODO}

\section{Área de estudo}

O estudo foi realizado na região de Guanhães, município de São João Evangelista, Minas Gerais (18³4'44,83”S; 42 53 '15,11’O). O município pertence à região fitoecológica de Floresta Estacional Semidecidual Montana (VELOSO et al., 1991; IBGE, 1993).

O fragmento estudado possui área total de 40 ha. Segundo a classificação climática de Köppen, o clima predominante na região é o Cwa (tropical de altitude, com verão quente e chuvoso e inverno frio e seco). A temperatura máxima ocorre no mês de março $\left(30,8^{\circ} \mathrm{C}\right)$ e a mínima no mês de julho $\left(10,7^{\circ} \mathrm{C}\right)$, sendo a máxima média de $28,1^{\circ} \mathrm{C}$ e a mínima média de $15,5^{\circ} \mathrm{C}$. A umidade relativa média é de $61,7 \%$; a máxima ocorre no mês de dezembro $(69,6 \%)$ e a mínima em setembro (52,1\%). A precipitação pluvial média mensal é de $98,6 \mathrm{~mm}$, sendo a máxima no mês de dezembro $(262,2 \mathrm{~mm})$ e a mínima em junho (10,8 mm) (SIF, 2003).

\section{Amostragem}

Foram instaladas oito parcelas retangulares de $1.000 \mathrm{~m}^{2}(10 \mathrm{~m} \times 100 \mathrm{~m})$ de forma sistemática, a fim de representar toda a área de estudo e contemplar a diversidade florística do fragmento.

A amostragem foi determinada para representação de uma parcela a cada cinco hectares, atingindo uma área amostrada equivalente a $2 \%$ da área total, conforme estudos fitossociológicos realizados por Hüller et al. (2011) e Silva et al. (2012). Todos os indivíduos dentro das parcelas com 
diâmetro a altura do peito (DAP) $\geq 5 \mathrm{~cm}$ tiveram seu DAP $(\mathrm{cm})$ e altura total $(\mathrm{m})$ medidos.

\section{Quantificação de carbono}

Para a estimativa do volume total da parte aérea das árvores foi utilizada a equação ajustada para florestas secundárias publicada pelo CETEC (1995):

$$
\begin{gathered}
\text { Vtcc }=0,000074 * \mathrm{DAP} 1,707348 * \mathrm{Ht}^{1,16873} \\
\mathrm{R}^{2}=97,30 \%
\end{gathered}
$$

Em que Vtcc = volume total com casca; DAP $=$ diâmetro medido a $1,30 \mathrm{~m}$ do solo em centímetros e $\mathrm{Ht}=$ altura total em metros.

Para cada espécie mostrada no fragmento foi atribuído o valor de densidade básica da madeira (LORENZI, 2002; CARVALHO, 2003; BOINA, 2008; LORENZI, 2009a; LORENZI, 2009b; AMARO, 2010). Estimou-se a biomassa da madeira de cada árvore pela multiplicação da densidade básica média da madeira por espécie pelo volume total existente acima do solo (RIBEIRO et al., 2010). A estimativa do carbono estocado na biomassa seca foi obtida pela multiplicação do fator 0,5 , considerando-se que a biomassa seca contém em média $50 \%$ de massa representada pelo carbono (FANG et al., 2001; SOARES e OLIVEIRA, 2002; FUKUDA et al., 2003; RIBEIRO et al., 2010). Para as árvores que foram identificadas apenas no gênero, foi utilizada uma densidade básica média para o gênero, segundo estes mesmos autores, e o carbono foi de $50 \%$. Pela totalização da quantidade de carbono de todos os indivíduos por espécie, estimou-se o estoque de carbono por hectare no fragmento florestal.

\section{Estrutura fitossociológica}

Foram calculados os índices de diversidade de Shannon (H') em nível de parcela. Com o objetivo de descrever a estrutura horizontal do fragmento, foram calculados, para cada espécie, os parâmetros de densidade absoluta (DA), que é o número de indivíduos por hectare de cada espécie na composição florística do fragmento; dominância absoluta (DoA), que se define como a medida da projeção do corpo da planta no solo por área; frequência absoluta (FA), que é a proporção de unidades amostrais com presença de cada espécie em relação ao número total de unidades amostrais.
Estes mesmos parâmetros são apresentados em termos relativos (DR; DoR e FR, respectivamente), ao se dividir o parâmetro absoluto de cada espécie pelo parâmetro de todas as espécies, além do índice de valor de importância representado pelo percentual de importância (VI) da média aritmética dos três valores relativos (SOARES et al., 2011).

Como critério de comparação, adotouse também a variável carbono por espécie (CA, em $\mathrm{kg} / \mathrm{ha}$ ), bem como seu valor relativo (CR) no cálculo do índice de valor de importância, a fim de avaliar o efeito dessa inclusão na valoração das espécies em comparação com o método tradicional. Assim, obteve-se pela soma de todos os valores relativos, o índice de valor de importância ampliado (VIA), incluindo na média aritmética esse último, o valor de carbono relativo das espécies na comunidade. Analisou-se a influência deste parâmetro na mudança do ranking de ordem de importância das espécies.

\section{RESULTADOS E DISCUSSÃO}

Foram relacionadas, nos 0,8 hectares de amostragem, 113 espécies com DAP $\geq 5 \mathrm{~cm}$, distribuídas em 34 famílias botânicas. A densidade estimada foi de 1.339 árvores ha-1 ${ }^{-1}$. Dessas espécies, $59,89 \%$ tiveram sua identificação em nível de espécie, 30,94\% em nível de gênero, 6,38\% em nível de família e $2,87 \%$ indeterminadas, sendo a identificação limitada devido à ausência de material botânico fértil durante o período do levantamento.

Das 34 famílias encontradas, as dez mais representativas em riqueza de espécies foram: Fabaceae Mimosoideae (11), Fabaceae Faboideae (9), Myrtacae (9), Bignoniaceae (6), Fabaceae Caesalpinioideae (6), Lauracae (6), Annonaceae (5), Apocynaceae (5), Meliaceae (4) e Rubiaceae (4). Estas famílias, em conjunto, representaram $57,52 \%$ das espécies amostradas. Vinte e três famílias apresentaram apenas uma espécie, sendo elas: Araliaceae, Boraginaceae, Celastraceae, Erythroxylaceae, Lecythidaceae, Nyctaginaceae, Ochnaceae, Urticaceae e Vochysiaceae. Os gêneros mais ricos foram: Myrcia, com 6 espécies, seguido por Machaerium com 5 e Inga com 4 espécies.

A composição das espécies amostradas demonstra que a vegetação apresenta-se característica às formações de Floresta Estacional Semidecidual de Mata Atlântica. Entretanto, foi observada a ocorrência de algumas espécies também encontradas no Cerrado, o que leva a reconhecer a 
região como uma possível área de transição.

Das 113 espécies arbóreas ocorrentes, duas constam na lista vermelha de espécies ameaçadas de extinção da flora de Minas Gerais (COPAM, 1997), sendo elas: Dalbergia Nigra (Vulnerável) e Melanoxylon brauna (Vulnerável). Neste trabalho não foi encontrada nenhuma espécie considerada rara ou de baixa densidade, de acordo com o critério de Martins (1979) e Kageyama e Gandra (1993).

Os índices de diversidade de Shannon (H') em nível de parcela variaram de 2,92 a 3,70 e para todo o fragmento este índice foi de 4,01.

Pinto et al. (2007), estudando o componente arbustivo-arbóreo em dois estágios sucessionais (inicial e madura) de floresta estacional semidecidual em Viçosa-MG, em que foram amostrados indivíduos com DAP $\geq 4,8 \mathrm{~cm}$, encontraram índice $\mathrm{H}^{\prime}$ de 3,31 para a floresta em estágio inicial e de 3,46 para a floresta madura. Carvalho et al. (2007), em trabalho realizado em um remanescente de Floresta Ombrófila Densa Submontana, no município de Rio Bonito, $\mathrm{RJ}$, encontraram $\mathrm{H}^{\prime}$ igual a 3,91. Em estudo desenvolvido em um fragmento de Mata Atlântica, Borém e Oliveira Filho (2002), utilizando amostragem sistemática em uma topossequência, encontraram $\mathrm{H}^{\prime}$ de 4,14. Gaspar (2008), em trabalho de monitoramento da flora em remanescente da Mata Atlântica, no mesmo município deste estudo, encontrou H' de 4,17. Os valores encontrados por estes autores estão em consonância com os encontrados neste trabalho, e indicam alta diversidade das florestas do Bioma Mata Atlântica, corroborando a representatividade do fragmento estudado em relação ao Bioma.

A estrutura horizontal normalmente empregada em estudos fitossociológicos engloba os parâmetros: densidade, dominância e frequência de cada espécie para definição do ranking de importância relativa de cada espécie. Neste estudo, considerou-se também como parâmetro, a capacidade de estocagem de carbono de cada espécie. O valor relativo desta variável foi incluído no cálculo de valor de importância e foi apresentado na Tabela 1.

As dez espécies de maior densidade relativa (DR) foram: Croton floribundus $(8,43 \%)$, Piptadenia gonoacantha (6,65\%), Guettarda viburnoides (4,49\%), Mabea fistulifera (4,31), Rollinia sylvatica (3,56\%), Machaerium brasiliense (3,46\%), Machaerium nyctitans (3,28\%), Vitex sellowiana (3,09\%), Apuleia leiocarpa (3\%), Platypodium elegans (2,9\%). Juntas, estas dez espécies apresentaram DR de 43,17\%, em relação ao total.

As espécies que apresentaram maiores frequências relativas (FR) foram: Croton floribundus (2,53\%), Machaerium brasiliense (2,53\%), Guettarda viburnoides (2,53\%), Rollinia sylvatica (2,53\%), Machaerium nyctitans (2,53\%), Piptadenia gonoacantha (2,22\%), Platypodium elegans (2,22\%), Apuleia leiocarpa (2,22\%), Myrcia sp. 2 (2,22\%) Myrcia amazonica (2,22\%). Juntas, estas dez espécies apresentaram frequências relativas (FR) de 23,75\%, em relação ao total.

As maiores dominâncias relativas (DoR) foram apresentadas pelas espécies: Piptadenia gonoacantha (8,33\%), Croton floribundus (7,59\%), Croton urucurana (5,68\%), Machaerium brasiliense (5,53\%), Platypodium elegans (5,22\%), Apuleia leiocarpa (4,41\%), Annona cacans (3,37\%), Guettarda viburnoides (3,34\%), Cariniana estrellensis (3,27\%), Pseudopiptadenia contorta (3,03\%). Juntas, estas dez espécies apresentaram DoR de $49,77 \%$, em relação ao total.

Os maiores estoques relativos de carbono (CR) foram observados nas espécies Croton urucurana $(8,86 \%), \quad$ Guettarda viburnoides (7,28\%), Croton floribundus (5,90\%), Platypodium elegans (5,77\%); Piptadenia gonoacantha (5,65\%), Cariniana estrellensis (5,20\%), Apuleia leiocarpa (5,04\%), Annona cacans (4,10\%), Pseudopiptadenia contorta (3,05\%), Machaerium brasiliense (3,05\%). Juntas, estas dez espécies apresentaram CR de $53,90 \%$, em relação ao total.

Seis das espécies mais representativas são comuns para as quatro variáveis, sendo elas: Croton floribundus, Piptadenia gonoacantha, Guettarda viburnoides, Platypodium elegans, Apuleia leiocarpa e Machaerium brasiliense.

Na Figura 1 são apresentadas as espécies de maior VI e VIA, com aproximadamente $50 \%$ dos valores relativos. Croton urucurana e Annona cacans subiram quatro posições e são espécies comumente encontradas em formações da Mata Atlântica de diferentes estágios sucessionais (MARANGON et al., 2003; RIBAS et al., 2003; MEYER et al., 2004; SILVA et al., 2004; NOBREGA et al., 2007, BRAGA et al., 2008).

Guettarda viburnoides, Machaerium nyctitans, Pseudopiptadenia contorta e Machaerium villosum subiram apenas uma posição. Já Machaerium brasiliense e Hyptidendron asperrimumcaiu caíram quatro posições devido as suas baixas estocagens de carbono em comparação 
TABELA 1: Parâmetros da estrutura horizontal do fragmento de Floresta Estacional Semidecidual Montana, ordenados pelo índice de importância ampliado (VIA).

TABLE 1: Horizontal structure parameters of the semi-deciduous forest fragment Montana, ordered by importance value extended (VIA).

\begin{tabular}{|c|c|c|c|c|c|c|c|c|c|c|c|c|c|c|c|}
\hline \multirow{2}{*}{ Nome Científico } & \multirow{2}{*}{$\mathrm{N}$} & \multirow{2}{*}{$\mathrm{AB}$} & \multirow{2}{*}{ DB } & \multirow{2}{*}{ DA } & \multirow{2}{*}{ DR } & \multirow{2}{*}{ FA } & \multirow{2}{*}{ FR } & \multirow{2}{*}{ DoA } & \multirow{2}{*}{ DoR } & \multirow{2}{*}{$\mathrm{VC}$} & \multirow{2}{*}{$\mathrm{CA}$} & \multirow{2}{*}{$\mathrm{CR}$} & \multirow{2}{*}{ VIA } & \multirow{2}{*}{ VI } & \multirow{2}{*}{$\frac{\Delta}{\text { Ranking }}$} \\
\hline & & & & & & & & & & & & & & & \\
\hline Croton floribundus Spreng. & 90 & 1,15 & $0,60^{(1)}$ & 113 & 8,43 & 100 & 2,53 & 1,44 & 7,59 & 8,01 & 3445 & 5,90 & 6,11 & 6,18 & $=$ \\
\hline Piptadenia gonoacantha (Mart.) J.F.Macbr. & 71 & 1,27 & $0,56^{(6)}$ & 89 & 6,65 & 88 & 2,22 & 1,58 & 8,33 & 7,49 & 3298 & 5,65 & 5,71 & 5,73 & $=$ \\
\hline Guettarda viburnoides Cham. \& Schltdl. & 48 & 0,51 & $0,73^{(2)}$ & 60 & 4,49 & 100 & 2,53 & 0,63 & 3,34 & 3,91 & 4246 & 7,28 & 4,41 & 3,45 & $\uparrow 1$ \\
\hline Croton urucurana Baill. & 17 & 0,86 & $0,83^{(1)}$ & 21 & 1,59 & 50 & 1,27 & 1,08 & 5,68 & 3,63 & 5170 & 8,86 & 4,35 & 2,84 & $\uparrow 4$ \\
\hline Platypodium elegans Vogel & 31 & 0,79 & $0,66^{(6)}$ & 39 & 2,90 & 88 & 2,22 & 0,99 & 5,22 & 4,06 & 3364 & 5,77 & 4,03 & 3,45 & $=$ \\
\hline Apuleia leiocarpa (Vogel) J.F.Macbr. & 32 & 0,67 & $0,62^{(6)}$ & 40 & 3,00 & 88 & 2,22 & 0,84 & 4,41 & 3,71 & 2939 & 5,04 & 3,67 & 3,21 & $=$ \\
\hline Machaerium brasiliense Vogel & 37 & 0,84 & $0,66^{(2)}$ & 46 & 3,46 & 100 & 2,53 & 1,05 & 5,53 & 4,50 & 1778 & 3,05 & 3,64 & 3,84 & $\downarrow 4$ \\
\hline Machaerium nyctitans (Vell. Conc.) Benth.) & 35 & 0,40 & $0,87^{(*)}$ & 44 & 3,28 & 100 & 2,53 & 0,50 & 2,66 & 2,97 & 1633 & 2,80 & 2,82 & 2,82 & $\uparrow 1$ \\
\hline Rollinia sylvatica (A.St.-Hil.) Mart. & 38 & 0,42 & $0,40^{(*)}$ & 48 & 3,56 & 100 & 2,53 & 0,52 & 2,76 & 3,16 & 836 & 1,43 & 2,57 & 2,95 & $\downarrow 2$ \\
\hline Annona cacans Warm. & 11 & 0,51 & $0,55^{(4)}$ & 14 & 1,03 & 50 & 1,27 & 0,64 & 3,37 & 2,20 & 2391 & 4,10 & 2,44 & 1,89 & $\uparrow 4$ \\
\hline Cariniana estrellensis (Raddi) Kuntze & 3 & 0,50 & $0,57^{(6)}$ & 4 & 0,28 & 25 & 0,63 & 0,62 & 3,27 & 1,78 & 3036 & 5,20 & 2,35 & 1,40 & $\uparrow 13$ \\
\hline Vitex sellowiana Cham. & 33 & 0,37 & $0,71^{(3)}$ & 41 & 3,09 & 63 & 1,58 & 0,46 & 2,43 & 2,76 & 1050 & 1,80 & 2,22 & 2,37 & $\downarrow 1$ \\
\hline Mabea fistulifera Mart. & 46 & 0,34 & $0,58^{(*)}$ & 58 & 4,31 & 38 & 0,95 & 0,42 & 2,23 & 3,27 & 791 & 1,35 & 2,21 & 2,49 & $\downarrow 3$ \\
\hline Myrcia sp. 2 & 31 & 0,28 & $0,86^{(*)}$ & 39 & 2,90 & 88 & 2,22 & 0,34 & 1,81 & 2,36 & 993 & 1,70 & 2,16 & 2,31 & $\downarrow 2$ \\
\hline $\begin{array}{l}\text { Pseudopiptadenia contorta } \\
\text { G.P.Lewis \& M.P.Lima }\end{array}$ & 9 & 0,46 & $0,47^{(6)}$ & 11 & 0,84 & 50 & 1,27 & 0,58 & 3,03 & 1,94 & 1782 & 3,05 & 2,05 & 1,71 & $\uparrow 1$ \\
\hline Machaerium villosum Vogel & 12 & 0,30 & $0,85^{(1)}$ & 15 & 1,12 & 75 & 1,90 & 0,38 & 2,00 & 1,56 & 1744 & 2,99 & 2,00 & 1,67 & $\uparrow 1$ \\
\hline Hyptidendron asperrimum (Epling) Harley & 18 & 0,39 & $0,43^{(2)}$ & 23 & 1,69 & 75 & 1,90 & 0,49 & 2,57 & 2,13 & 864 & 1,48 & 1,91 & 2,05 & $\downarrow 4$ \\
\hline Persea pyrifolia Nees & 10 & 0,30 & $0,68^{(1)}$ & 13 & 0,94 & 63 & 1,58 & 0,37 & 1,97 & 1,45 & 1459 & 2,50 & 1,75 & 1,49 & $\uparrow 3$ \\
\hline Nectandra oppositifolia Nees & 26 & 0,23 & $0,54^{(1)}$ & 33 & 2,43 & 63 & 1,58 & 0,28 & 1,49 & 1,96 & 744 & 1,28 & 1,69 & 1,84 & $\downarrow 4$ \\
\hline Dalbergia nigra (Vell.) Allemão ex Benth. & 13 & 0,22 & $0,71^{(5)}$ & 16 & 1,22 & 75 & 1,90 & 0,28 & 1,45 & 1,34 & 937 & 1,61 & 1,54 & 1,52 & $=$ \\
\hline Myrcia sp. 1 & 19 & 0,18 & $0,86^{(*)}$ & 24 & 1,78 & 75 & 1,90 & 0,22 & 1,15 & 1,47 & 549 & 0,94 & 1,44 & 1,61 & $\downarrow 3$ \\
\hline Casearia sylvestris $\mathrm{Sw}$. & 22 & 0,15 & $0,84^{(1)}$ & 28 & 2,06 & 63 & 1,58 & 0,19 & 0,99 & 1,53 & 564 & 0,97 & 1,40 & 1,55 & $\downarrow 3$ \\
\hline Cecropia hololeuca Miq. & 10 & 0,31 & $0,43^{(1)}$ & 13 & 0,94 & 38 & 0,95 & 0,38 & 2,02 & 1,48 & 963 & 1,65 & 1,39 & 1,30 & $\uparrow 3$ \\
\hline Inga sp. 2 & 9 & 0,28 & $0,62^{(*)}$ & 11 & 0,84 & 25 & 0,63 & 0,35 & 1,83 & 1,34 & 1264 & 2,17 & 1,37 & 1,10 & $\uparrow 6$ \\
\hline Luehea grandiflora Mart. \& Zucc. & 13 & 0,18 & $0,64^{(1)}$ & 16 & 1,22 & 75 & 1,90 & 0,22 & 1,16 & 1,19 & 614 & 1,05 & 1,33 & 1,43 & $\downarrow 3$ \\
\hline Vismia guianensis (Aubl.) Pers. & 21 & 0,16 & $0,64^{(*)}$ & 26 & 1,97 & 50 & 1,27 & 0,20 & 1,05 & 1,51 & 470 & 0,81 & 1,27 & 1,43 & $\downarrow 3$ \\
\hline Myrcia amazonica DC. & 14 & 0,10 & $0,86^{(*)}$ & 18 & 1,31 & 88 & 2,22 & 0,13 & 0,66 & 0,99 & 500 & 0,86 & 1,26 & 1,40 & $\downarrow 2$ \\
\hline Inga sp. 1 & 10 & 0,13 & $0,62^{(*)}$ & 13 & 0,94 & 50 & 1,27 & 0,16 & 0,86 & 0,90 & 656 & 1,12 & 1,05 & 1,02 & $\uparrow 4$ \\
\hline Siparuna arianeae V. Pereira & 19 & 0,07 & $0,56^{(6)}$ & 24 & 1,78 & 63 & 1,58 & 0,09 & 0,48 & 1,13 & 132 & 0,23 & 1,02 & 1,28 & $\downarrow 2$ \\
\hline Jacaranda macrantha Cham. & 16 & 0,10 & $0,58^{(1)}$ & 20 & 1,50 & 50 & 1,27 & 0,13 & 0,66 & 1,08 & 225 & 0,39 & 0,95 & 1,14 & $\downarrow 2$ \\
\hline Copaifera langsdorffii Desf. & 4 & 0,17 & $0,60^{(6)}$ & 5 & 0,37 & 50 & 1,27 & 0,21 & 1,13 & 0,75 & 583 & 1,00 & 0,94 & 0,92 & $\uparrow 1$ \\
\hline $\begin{array}{l}\text { Sparattosperma leucanthum (Vell.) } \\
\text { K.Schum. }\end{array}$ & 11 & 0,18 & $0,57^{(1)}$ & 14 & 1,03 & 13 & 0,32 & 0,22 & 1,18 & 1,11 & 593 & 1,02 & 0,89 & 0,84 & $\uparrow 5$ \\
\hline Inga cylindrica (Vell.) Mart. & 9 & 0,17 & $0,96^{(1)}$ & 11 & 0,84 & 63 & 1,59 & 0,21 & 1,11 & 0,97 & 411 & 0,70 & 1,06 & 1,18 & $\downarrow 2$ \\
\hline Maytenus salicifolia Reissek & 10 & 0,03 & $0,86^{(*)}$ & 13 & 0,94 & 63 & 1,58 & 0,04 & 0,21 & 0,57 & 447 & 0,77 & 0,87 & 0,91 & $=$ \\
\hline Bauhinia sp. & 16 & 0,05 & $0,85^{(*)}$ & 20 & 1,50 & 50 & 1,27 & 0,06 & 0,32 & 0,91 & 106 & 0,18 & 0,82 & 1,03 & $\downarrow 4$ \\
\hline Zanthoxylum rhoifolium Lam. & 11 & 0,08 & $0,89^{(*)}$ & 14 & 1,03 & 38 & 0,95 & 0,10 & 0,52 & 0,78 & 339 & 0,58 & 0,77 & 0,83 & $\uparrow 3$ \\
\hline Trichilia pallida $\mathrm{Sw}$. & 17 & 0,07 & $0,74^{(2)}$ & 21 & 1,59 & 25 & 0,63 & 0,09 & 0,47 & 1,03 & 175 & 0,30 & 0,75 & 0,90 & $\downarrow 1$ \\
\hline Myrcia fallax (Rich.) DC. & 9 & 0,04 & $0,86^{(*)}$ & 11 & 0,84 & 63 & 1,58 & 0,05 & 0,25 & 0,55 & 143 & 0,24 & 0,73 & 0,89 & $\downarrow 1$ \\
\hline Lauraceae & 11 & 0,11 & $0,64^{(*)}$ & 14 & 1,03 & 38 & 0,95 & 0,14 & 0,75 & 0,89 & 62 & 0,11 & 0,71 & 0,91 & $\downarrow 4$ \\
\hline Helicteres sp. & 7 & 0,04 & $0,69^{(*)}$ & 9 & 0,66 & 63 & 1,58 & 0,05 & 0,25 & 0,45 & 107 & 0,18 & 0,67 & 0,83 & $=$ \\
\hline Siparuna guianensis Aubl. & 10 & 0,05 & $0,56^{(6)}$ & 13 & 0,94 & 38 & 0,95 & 0,06 & 0,31 & 0,62 & 100 & 0,17 & 0,59 & 0,73 & $=$ \\
\hline Byrsonima sp. 3 & 7 & 0,08 & $0,72^{(*)}$ & 9 & 0,66 & 25 & 0,63 & 0,10 & 0,53 & 0,59 & 271 & 0,46 & 0,57 & 0,61 & $=$ \\
\hline Matayba elaegnoides Radlk. & 5 & 0,09 & $0,85^{(*)}$ & 6 & 0,47 & 25 & 0,63 & 0,11 & 0,58 & 0,52 & 337 & 0,58 & 0,56 & 0,56 & $\uparrow 1$ \\
\hline
\end{tabular}

Continua ... 
TABELA 1: Continuação ...

TABLE 1: Continued ...

\begin{tabular}{|c|c|c|c|c|c|c|c|c|c|c|c|c|c|c|c|}
\hline \multirow{2}{*}{ Nome Científico } & \multirow{2}{*}{$\mathrm{N}$} & \multirow{2}{*}{$\mathrm{AB}$} & \multirow{2}{*}{ DB } & \multirow{2}{*}{ DA } & \multirow{2}{*}{ DR } & \multirow{2}{*}{ FA } & \multirow{2}{*}{ FR } & \multirow{2}{*}{ DoA } & \multirow{2}{*}{ DoR } & \multirow{2}{*}{$\mathrm{VC}$} & \multirow{2}{*}{$\mathrm{CA}$} & \multirow{2}{*}{$\mathrm{CR}$} & \multirow{2}{*}{ VIA } & \multirow{2}{*}{ VI } & \multirow{2}{*}{$\frac{\Delta}{\text { Ranking }}$} \\
\hline & & & & & & & & & & & & & & & \\
\hline Melanoxylon brauna Schott & 4 & 0,03 & $1,05^{(1)}$ & 5 & 0,37 & 38 & 0,95 & 0,04 & 0,22 & 0,30 & 266 & 0,46 & 0,50 & 0,51 & $\uparrow 6$ \\
\hline Aspidosperma sp. & 4 & 0,04 & $0,81^{(*)}$ & 5 & 0,37 & 38 & 0,95 & 0,05 & 0,28 & 0,33 & 219 & 0,38 & 0,49 & 0,53 & $\uparrow 3$ \\
\hline Allophylus edulis (A.St.-Hil. et al.) Radlk. & 6 & 0,07 & $0,42^{(6)}$ & 8 & 0,56 & 25 & 0,63 & 0,09 & 0,47 & 0,51 & 166 & 0,29 & 0,49 & 0,55 & $\downarrow 1$ \\
\hline Cordia sellowiana Cham. & 6 & 0,07 & $0,41^{(5)}$ & 8 & 0,56 & 25 & 0,63 & 0,09 & 0,45 & 0,51 & 158 & 0,27 & 0,48 & 0,55 & $\downarrow 1$ \\
\hline Pouteria sp. & 3 & 0,04 & $0,95^{(*)}$ & 4 & 0,28 & 38 & 0,95 & 0,05 & 0,28 & 0,28 & 230 & 0,39 & 0,48 & 0,50 & $\uparrow 3$ \\
\hline Fabaceae Mimosoideae & 3 & 0,06 & $0,79^{(*)}$ & 4 & 0,28 & 25 & 0,63 & 0,08 & 0,40 & 0,34 & 345 & 0,59 & 0,48 & 0,44 & $\uparrow 8$ \\
\hline Miconia cinnamomifolia (DC.) Naudin & 9 & 0,07 & $0,73^{(1)}$ & 11 & 0,84 & 13 & 0,32 & 0,08 & 0,44 & 0,64 & 174 & 0,30 & 0,47 & 0,53 & $\downarrow 1$ \\
\hline Tibouchina granulosa(Desr.)Cogn. & 5 & 0,01 & $0,61^{(*)}$ & 6 & 0,47 & 50 & 1,27 & 0,02 & 0,08 & 0,27 & 20 & 0,04 & 0,46 & 0,60 & $\downarrow 8$ \\
\hline Lacistema pubescens Mart. & 4 & 0,05 & $0,72^{(* *)}$ & 5 & 0,37 & 25 & 0,63 & 0,07 & 0,35 & 0,36 & 281 & 0,48 & 0,46 & 0,45 & $\uparrow 4$ \\
\hline Astronium graveolens Jacq. & 3 & 0,06 & $0,97^{(1)}$ & 4 & 0,28 & 25 & 0,63 & 0,07 & 0,39 & 0,34 & 271 & 0,46 & 0,44 & 0,44 & $\uparrow 5$ \\
\hline Tapirira guianensis Aubl. & 4 & 0,09 & $0,46^{(6)}$ & 5 & 0,37 & 13 & 0,32 & 0,11 & 0,57 & 0,47 & 291 & 0,50 & 0,44 & 0,42 & $\uparrow 5$ \\
\hline Psidium sp. & 6 & 0,02 & $0,91^{(*)}$ & 8 & 0,56 & 38 & 0,95 & 0,02 & 0,10 & 0,33 & 41 & 0,07 & 0,42 & 0,54 & $\downarrow 8$ \\
\hline Guatteria sp. 2 & 5 & 0,04 & $0,63^{(*)}$ & 6 & 0,47 & 25 & 0,63 & 0,05 & 0,28 & 0,38 & 135 & 0,23 & 0,40 & 0,46 & $\downarrow 1$ \\
\hline $\begin{array}{l}\text { Senna macranthera (Collad.) H.S.Irwin \& } \\
\text { Barneby }\end{array}$ & 4 & 0,02 & $0,90^{(*)}$ & 5 & 0,37 & 38 & 0,95 & 0,02 & 0,12 & 0,25 & 96 & 0,17 & 0,40 & 0,48 & $\downarrow 5$ \\
\hline Licania sp. 2 & 5 & 0,05 & $0,76^{(*)}$ & 6 & 0,47 & 13 & 0,32 & 0,07 & 0,35 & 0,41 & 240 & 0,41 & 0,39 & 0,38 & $\uparrow 5$ \\
\hline $\begin{array}{l}\text { Schefflera morototoni (Aubl.) Maguire et } \\
\text { al. }\end{array}$ & 3 & 0,03 & $0,62^{(1)}$ & 4 & 0,28 & 38 & 0,95 & 0,03 & 0,18 & 0,23 & 75 & 0,13 & 0,38 & 0,47 & $\downarrow 5$ \\
\hline Amaioua guianensis Aubl. & 4 & 0,02 & $0,67^{(2)}$ & 5 & 0,37 & 38 & 0,95 & 0,02 & 0,10 & 0,24 & 34 & 0,06 & 0,37 & 0,48 & $\downarrow 7$ \\
\hline Hortia arborea Engl. & 2 & 0,05 & $0,83^{(5)}$ & 3 & 0,19 & 13 & 0,32 & 0,07 & 0,36 & 0,27 & 342 & 0,59 & 0,36 & 0,29 & $\uparrow 14$ \\
\hline Qualea sp. & 2 & 0,05 & $0,83^{(*)}$ & 3 & 0,19 & 13 & 0,32 & 0,06 & 0,33 & 0,26 & 340 & 0,58 & 0,36 & 0,28 & $\uparrow 17$ \\
\hline Acacia $\mathrm{sp}$. & 6 & 0,05 & $0,89^{(*)}$ & 8 & 0,56 & 13 & 0,32 & 0,06 & 0,32 & 0,44 & 120 & 0,21 & 0,35 & 0,40 & $\downarrow 3$ \\
\hline $\begin{array}{l}\text { Himatanthus lancifolius } \quad \text { (Müll.Arg.) } \\
\text { Woodson }\end{array}$ & 3 & 0,02 & $0,71^{(*)}$ & 4 & 0,28 & 25 & 0,63 & 0,02 & 0,12 & 0,20 & 191 & 0,33 & 0,34 & 0,35 & $\uparrow 4$ \\
\hline Pesquiera sp. & 4 & 0,03 & $0,60^{(*)}$ & 5 & 0,37 & 25 & 0,63 & 0,04 & 0,19 & 0,28 & 91 & 0,16 & 0,34 & 0,40 & $\downarrow 4$ \\
\hline Byrsonima sp. 1 & 2 & 0,04 & $0,72^{(*)}$ & 3 & 0,19 & 25 & 0,63 & 0,04 & 0,23 & 0,21 & 163 & 0,28 & 0,33 & 0,35 & $\uparrow 3$ \\
\hline Lonchocarpus sp. 1 & 4 & 0,02 & $0,77^{(*)}$ & 5 & 0,37 & 25 & 0,63 & 0,02 & 0,12 & 0,25 & 88 & 0,15 & 0,32 & 0,37 & $\downarrow 3$ \\
\hline Campomanesia sp. & 4 & 0,02 & $0,84^{(*)}$ & 5 & 0,37 & 25 & 0,63 & 0,02 & 0,11 & 0,24 & 61 & 0,10 & 0,30 & 0,37 & $\downarrow 3$ \\
\hline Erythroxylum pelleterianum A.St.-Hil. & 5 & 0,01 & $0,89^{(*)}$ & 6 & 0,47 & 25 & 0,63 & 0,01 & 0,08 & 0,27 & 19 & 0,03 & 0,30 & 0,39 & $\downarrow 7$ \\
\hline Sloanea sp. 1 & 3 & 0,03 & $0,91^{(*)}$ & 4 & 0,28 & 25 & 0,63 & 0,04 & 0,19 & 0,23 & 51 & 0,09 & 0,30 & 0,37 & $\downarrow 4$ \\
\hline $\begin{array}{l}\text { Pseudobombax } \quad \text { grandiflorum } \quad \text { (Cav.) } \\
\text { A.Robyns }\end{array}$ & 3 & 0,03 & $0,39^{(1)}$ & 4 & 0,28 & 25 & 0,63 & 0,04 & 0,18 & 0,23 & 54 & 0,09 & 0,30 & 0,37 & $\downarrow 4$ \\
\hline Tabebuia serratifolia (Vahl) Nicholson & 3 & 0,04 & $1,08^{(*)}$ & 4 & 0,28 & 13 & 0,32 & 0,05 & 0,28 & 0,28 & 171 & 0,29 & 0,29 & 0,29 & $\uparrow 4$ \\
\hline Myrcia sp. 3 & 2 & 0,03 & $0,86^{(*)}$ & 3 & 0,19 & 25 & 0,63 & 0,04 & 0,22 & 0,20 & 74 & 0,13 & 0,29 & 0,35 & $\downarrow 3$ \\
\hline $\begin{array}{l}\text { Eremanthus erythropappus } \\
\text { MacLeish }\end{array}$ & 2 & 0,03 & $0,99^{(3)}$ & 3 & 0,19 & 13 & 0,32 & 0,03 & 0,17 & 0,18 & 283 & 0,48 & 0,29 & 0,23 & $\uparrow 9$ \\
\hline Ocotea sp. & 2 & 0,03 & $0,52^{(*)}$ & 3 & 0,19 & 25 & 0,63 & 0,03 & 0,17 & 0,18 & 71 & 0,12 & 0,28 & 0,33 & $\downarrow 4$ \\
\hline Fabaceae caesalpinioideae & 2 & 0,02 & $0,90^{(*)}$ & 3 & 0,19 & 25 & 0,63 & 0,03 & 0,14 & 0,16 & 73 & 0,13 & 0,27 & 0,32 & $\downarrow 3$ \\
\hline Annonaceae & 3 & 0,01 & $0,63^{(*)}$ & 4 & 0,28 & 25 & 0,63 & 0,02 & 0,08 & 0,18 & 26 & 0,04 & 0,26 & 0,33 & $\downarrow 5$ \\
\hline Licania sp. 1 & 2 & 0,01 & $0,76^{(*)}$ & 3 & 0,19 & 25 & 0,63 & 0,02 & 0,09 & 0,14 & 49 & 0,08 & 0,25 & 0,30 & $\downarrow 4$ \\
\hline Ocotea odorifera (Vell.) Rohwer & 3 & 0,02 & $0,52^{(6)}$ & 4 & 0,28 & 13 & 0,32 & 0,03 & 0,16 & 0,22 & 93 & 0,16 & 0,23 & 0,25 & $\uparrow 2$ \\
\hline Eugenia sp. & 2 & 0,01 & $0,82^{(*)}$ & 3 & 0,19 & 25 & 0,63 & 0,01 & 0,05 & 0,12 & 23 & 0,04 & 0,23 & 0,29 & $\downarrow 3$ \\
\hline $\begin{array}{l}\text { Phyllostemonodaphne geminiflora (Mez) } \\
\text { Kosterm. }\end{array}$ & 2 & 0,01 & $0,64^{(*)}$ & 3 & 0,19 & 25 & 0,63 & 0,01 & 0,05 & 0,12 & 17 & 0,03 & 0,22 & 0,29 & $\downarrow 3$ \\
\hline Chrysophyllum sp. & 3 & 0,03 & $0,75^{(*)}$ & 4 & 0,28 & 13 & 0,32 & 0,03 & 0,18 & 0,23 & 67 & 0,11 & 0,22 & 0,26 & $\downarrow 2$ \\
\hline Inga edulis Mart. & 1 & 0,03 & $0,76^{(2)}$ & 1 & 0,09 & 13 & 0,32 & 0,04 & 0,22 & 0,16 & 114 & 0,19 & 0,21 & 0,21 & $\uparrow 1$ \\
\hline Bathysa nicholsonii K.Schum. & 3 & 0,02 & $0,64^{(2)}$ & 4 & 0,28 & 13 & 0,32 & 0,02 & 0,12 & 0,20 & 32 & 0,05 & 0,19 & 0,24 & $\downarrow 2$ \\
\hline Himatanthus sp. & 1 & 0,02 & $0,71^{(*)}$ & 1 & 0,09 & 13 & 0,32 & 0,03 & 0,15 & 0,12 & 67 & 0,11 & 0,17 & 0,19 & $\uparrow 1$ \\
\hline
\end{tabular}

Continua ... 
TABELA 1: Continuação ...

TABLE 1: Continued ...

\begin{tabular}{|c|c|c|c|c|c|c|c|c|c|c|c|c|c|c|c|}
\hline Nome Científico & $\mathrm{N}$ & $\mathrm{AB}$ & DB & DA & DR & FA & FR & DoA & DoR & $\mathrm{VC}$ & $\mathrm{CA}$ & $\mathrm{CR}$ & VIA & VI & $\frac{\Delta}{\text { Ranking }}$ \\
\hline Casearia sp. & 2 & 0,02 & $0,55^{(6)}$ & 3 & 0,19 & 13 & 0,32 & 0,02 & 0,11 & 0,15 & 32 & 0,05 & 0,17 & 0,20 & $\downarrow 1$ \\
\hline Sapotaceae & 2 & 0,01 & $0,84^{(*)}$ & 3 & 0,19 & 13 & 0,32 & 0,01 & 0,07 & 0,13 & 39 & 0,07 & 0,16 & 0,19 & $=$ \\
\hline Guapira opposita (Vell.) Reitz & 1 & 0,01 & $0,49^{(5)}$ & 1 & 0,09 & 13 & 0,32 & 0,02 & 0,08 & 0,09 & 72 & 0,12 & 0,15 & 0,16 & $=$ \\
\hline Fabaceae faboideae & 1 & 0,01 & $0,81^{(*)}$ & 1 & 0,09 & 13 & 0,32 & 0,01 & 0,08 & 0,08 & 48 & 0,08 & 0,14 & 0,16 & $=$ \\
\hline Indeterminada 1 & 1 & 0,01 & $0,72^{(* *)}$ & 1 & 0,09 & 13 & 0,32 & 0,01 & 0,08 & 0,08 & 30 & 0,05 & 0,14 & 0,16 & $=$ \\
\hline Diatenopteryx sorbifolia Radlk & 1 & 0,01 & $0,69^{(5)}$ & 1 & 0,09 & 13 & 0,32 & 0,01 & 0,07 & 0,08 & 29 & 0,05 & 0,13 & 0,16 & $=$ \\
\hline Machaerium sp. 1 & 1 & 0,01 & $0,87^{(*)}$ & 1 & 0,09 & 13 & 0,32 & 0,01 & 0,05 & 0,07 & 30 & 0,05 & 0,13 & 0,14 & $\uparrow 11$ \\
\hline Inga marginata Willd. & 1 & 0,01 & $0,62^{(*)}$ & 1 & 0,09 & 13 & 0,32 & 0,01 & 0,05 & 0,07 & 22 & 0,04 & 0,12 & 0,15 & $\downarrow 1$ \\
\hline Stryphnodendron polyphyllum Mart. & 1 & 0,01 & $1,19^{(*)}$ & 1 & 0,09 & 13 & 0,32 & 0,01 & 0,03 & 0,06 & 28 & 0,05 & 0,12 & 0,15 & $\downarrow 1$ \\
\hline Jacaranda cf. puberula Cham. & 1 & 0,01 & $0,58^{(1)}$ & 1 & 0,09 & 13 & 0,32 & 0,01 & 0,05 & 0,07 & 14 & 0,02 & 0,12 & 0,15 & $\downarrow 1$ \\
\hline Sloanea sp. 2 & 1 & 0,01 & $0,91^{(*)}$ & 1 & 0,09 & 13 & 0,32 & 0,01 & 0,05 & 0,07 & 13 & 0,02 & 0,12 & 0,15 & $\downarrow 1$ \\
\hline Piptocarpha macropoda Baker & 1 & 0,01 & $0,65^{(*)}$ & 1 & 0,09 & 13 & 0,32 & 0,01 & 0,04 & 0,07 & 15 & 0,03 & 0,12 & 0,15 & $\downarrow 1$ \\
\hline Ourateae sp. & 1 & 0,01 & $0,64^{(*)}$ & 1 & 0,09 & 13 & 0,32 & 0,01 & 0,04 & 0,07 & 15 & 0,03 & 0,12 & 0,15 & $\downarrow 1$ \\
\hline Myrcia formosiana A. DC. & 1 & 0,00 & $0,86^{(*)}$ & 1 & 0,09 & 13 & 0,32 & 0,01 & 0,03 & 0,06 & 14 & 0,02 & 0,12 & 0,15 & $\downarrow 1$ \\
\hline Indeterminada 3 & 1 & 0,01 & $0,72^{(* *)}$ & 1 & 0,09 & 13 & 0,32 & 0,01 & 0,03 & 0,06 & 14 & 0,02 & 0,12 & 0,15 & $\downarrow 1$ \\
\hline Indeterminada 2 & 1 & 0,01 & $0,72^{(* *)}$ & 1 & 0,09 & 13 & 0,32 & 0,01 & 0,03 & 0,06 & 12 & 0,02 & 0,12 & 0,15 & $\downarrow 1$ \\
\hline Apocynaceae & 1 & 0,00 & $0,76^{(*)}$ & 1 & 0,09 & 13 & 0,32 & 0,01 & 0,03 & 0,05 & 12 & 0,02 & 0,12 & 0,14 & $\uparrow 2$ \\
\hline Vismia cf. brasiliensis & 1 & 0,00 & $0,64^{(2)}$ & 1 & 0,09 & 13 & 0,32 & 0,01 & 0,03 & 0,06 & 9 & 0,02 & 0,11 & 0,15 & $\downarrow 2$ \\
\hline Tabebuia sp. & 1 & 0,00 & $0,87^{(*)}$ & 1 & 0,09 & 13 & 0,32 & 0,01 & 0,03 & 0,06 & 6 & 0,01 & 0,11 & 0,15 & $\downarrow 2$ \\
\hline Alseis sp. & 1 & 0,00 & $0,85^{(*)}$ & 1 & 0,09 & 13 & 0,32 & 0,00 & 0,02 & 0,06 & 11 & 0,02 & 0,11 & 0,14 & $=$ \\
\hline Machaerium sp. 2 & 1 & 0,00 & $0,87^{(*)}$ & 1 & 0,09 & 13 & 0,32 & 0,00 & 0,02 & 0,06 & 9 & 0,02 & 0,11 & 0,14 & $=$ \\
\hline Lonchocarpus sp. 2 & 1 & 0,00 & $0,77^{(*)}$ & 1 & 0,09 & 13 & 0,32 & 0,00 & 0,02 & 0,06 & 8 & 0,01 & 0,11 & 0,14 & $=$ \\
\hline Cabralea canjerana (Vell.) Mart. & 1 & 0,00 & $0,69^{(1)}$ & 1 & 0,09 & 13 & 0,32 & 0,00 & 0,02 & 0,05 & 8 & 0,01 & 0,11 & 0,14 & $=$ \\
\hline Byrsonima sp. 2 & 1 & 0,00 & $0,72^{(*)}$ & 1 & 0,09 & 13 & 0,32 & 0,00 & 0,02 & 0,06 & 6 & 0,01 & 0,11 & 0,14 & $=$ \\
\hline Casearia cf. gossypiosperma Briq. & 1 & 0,00 & $0,55^{(6)}$ & 1 & 0,09 & 13 & 0,32 & 0,00 & 0,02 & 0,06 & 5 & 0,01 & 0,11 & 0,14 & $=$ \\
\hline Trichilia sp. & 1 & 0,00 & $0,79^{(*)}$ & 1 & 0,09 & 13 & 0,32 & 0,00 & 0,02 & 0,06 & 4 & 0,01 & 0,11 & 0,14 & $=$ \\
\hline $\begin{array}{l}\text { Tabebuia chrysotricha (Mart. ex A.DC.) } \\
\text { Standl. }\end{array}$ & 1 & 0,00 & $0,87^{(*)}$ & 1 & 0,09 & 13 & 0,32 & 0,00 & 0,01 & 0,05 & 7 & 0,01 & 0,11 & 0,14 & $=$ \\
\hline Galipea jasminiflora (A.St.-Hil.) Engl. & 1 & 0,00 & $0,89^{(*)}$ & 1 & 0,09 & 13 & 0,32 & 0,00 & 0,01 & 0,05 & 4 & 0,01 & 0,11 & 0,14 & $=$ \\
\hline Total & 1068 & 15 & - & 1339 & 100 & 3950 & 100 & 19 & 100 & 100 & 58347 & 100 & 100 & 100 & \\
\hline
\end{tabular}

Em que: $\mathrm{N}=$ número de indivíduos por hectare; $\mathrm{AB}=$ área basal $\left(\mathrm{m}^{2} / \mathrm{ha}\right) ; \mathrm{DB}=$ densidade básica da madeira $\left(\mathrm{g} / \mathrm{cm}^{3}\right)$; ${ }^{(1)}$ Lorenzi (2002); (2) Lorenzi (2009a); ${ }^{(3)}$ Lorenzi (2009b); (4) Carvalho (2003); (5) Boina (2008); (6) Amaro (2010); (*) Média de gênero ou família segundo (1), (2) e (3); (**) média geral de densidade básica, por serem espécies indeterminadas; $\mathrm{DA}=$ densidade absoluta (ind./ha); $\mathrm{DR}=$ densidade relativa (\%); $\mathrm{FA}=$ frequência absoluta; $\mathrm{FR}=$ frequência relativa (\%); DoA = dominância absoluta; DoR = dominância relativa (\%); VC = valor de cobertura (\%); $\mathrm{CA}=$ estoque de carbono absoluto ( $\mathrm{Kg} / \mathrm{ha}) ; \mathrm{CR}=$ estoque de carbono relativo (\%); VIA = índice de valor de importância ampliado (\%), considerando a variável carbono; VI = índice de valor de importância (\%); e $\Delta$ Ranking $=$ deslocamento no ranking dada a inclusão da variável carbono. ( $\uparrow$ ) Subiu j posições no Ranking; ( $\downarrow$ ) Desceu j posições no Ranking.

com as outras, por consequência da baixa densidade da madeira e/ou menor concentração de carbono na biomassa. Rollinia sylvatica e Myrcia sp. 2 desceram duas posições, enquanto Vitex sellowiana e Mabea fistulifera caíram uma e três posições respectivamente, também devido as suas baixas produções de biomassa. Croton floribundus, Piptadenia gonoacantha, Platypodium elegans, Apuleia leiocarpa não variaram no ranking, mas estão entre as seis espécies de maior VI, além de serem abundantes nas florestas estacionais semideciduais (BOINA, 2008; GASPAR, 2008), sendo essenciais nos projetos de restauração florestal em formações secundárias.

Considerando o parâmetro capacidade de estocagem de carbono, cerca de $20 \%$ das espécies não apresentaram mudança no ranking em termos de valor de importância (Figura 2). Houve uma 
maior tendência de mudanças negativas de posição no ranking, com a maioria das espécies (15\%) caindo uma posição.

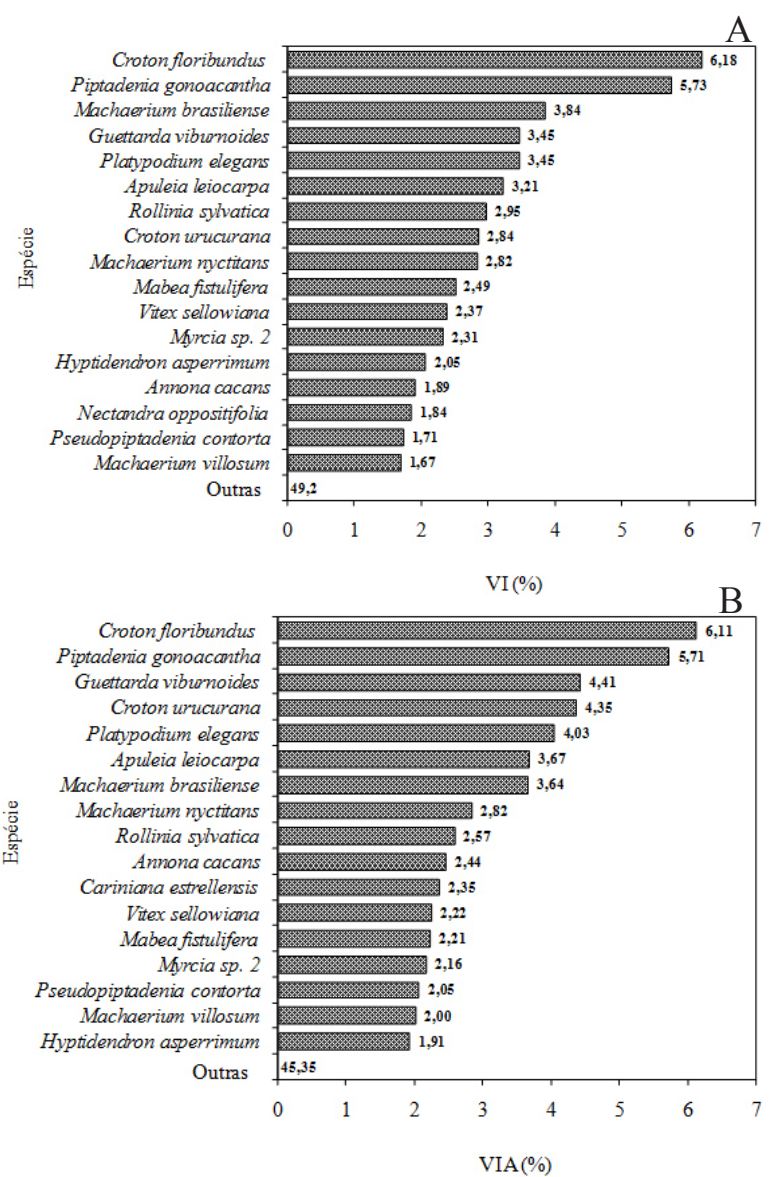

FIGURA 1: Participação das dezessete espécies de maior valor de importância (VI\%), observadas no fragmento florestal. A: índice de importância; B: índice de importância ampliado.

FIGURE 1: Participation of the seventeen species with greatest importance value (VI\%) observed in the forest fragment. A: importance index; B: Large importance index.

Em termos de mudanças positivas, a maioria das espécies subiu apenas uma posição $(7,1 \%)$, seguida pelas espécies que subiram 3 e 4 posições (5,3\%). Eremanthus erythropappus, Machaerium sp. 1, Cariniana estrellensis, Hortia arborea e Qualea sp. foram as espécies que mais ganharam posições no ranking, subindo 9, 11, 13, 14 e 17 posições, respectivamente (Tabela 1 e Figura 1). As espécies que subiram no ranking devem ser analisadas como potenciais para serem incluídas em projetos de reflorestamento ou restauração de

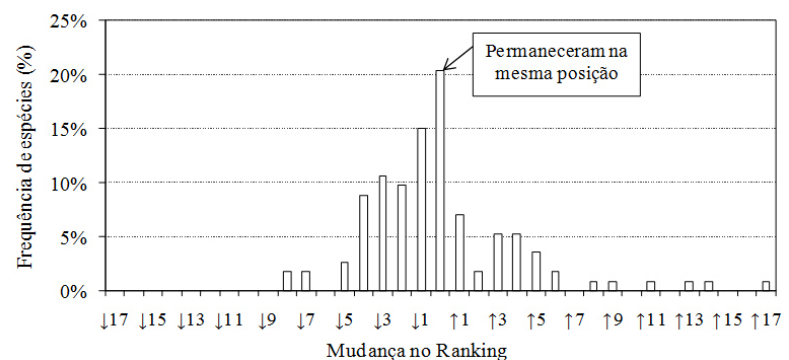

FIGURA 2: Frequência de espécies que mudaram de posição no ranking de importância na estrutura horizontal da análise fitossociológica.

FIGURE 2: Frequency of species that changed position in the importance ranking of the horizontal structure in the phytosociological analysis.

fragmentos florestais, pelo diferencial apresentado em termos de "sequestrar e estocar carbono".

A espécie Eremanthus erythropappus apresenta a característica de crescer em solos rasos, pobres e pedregosos, com crescimento inicial acelerado, formando povoamentos bastante homogêneos, os quais fornecem madeira de elevada durabilidade natural (RIZZINI, 1979). Devido as suas características de crescimento, pode ser recomendada para programas de restauração florestal (PÉREZ, 2001). A sua inclusão nestes programas torna-se ainda mais interessante ao considerar a capacidade desta em estocar carbono, pois esta espécie foi uma das que mais ganharam posições (9) em termos de valor de importância na área de estudo quando se considerou a capacidade de estocagem de carbono, embora tenha apresentado baixo VI $(0,23 \%)$.

Hortia arborea é uma espécie secundária tardia, apresentou baixo VI (0,29\%) neste estudo, o que está de acordo com outros trabalhos em locais com a mesma formação florestal (SILVA et al., 2000; LOUZADA, 2002, BOINA, 2008). Apesar de sua baixa ocorrência, não deve ser excluída de programas de restauração, já que a espécie, além de ser característica de estágio avançado de regeneração (BRASIL, 2007) é muito utilizada para fins medicinais (CARVALHO, 2003). Essa espécie subiu 14 posições no ranking de valor de importância após a inclusão da variável estoque de carbono.

Entre as espécies de maior VIA, Cariniana estrellensis foi a que mais variou, subindo 13 posições no ranking, mostrando-se altamente 
recomendada na restauração, constando na lista de espécies recomendadas para restauração da Mata Atlântica proposta por Kalil Filho et al. (2002) e presente em vários levantamentos florísticos na Mata Atlântica (BORÉM e OLIVEIRA-FILHO, 2002; SILVA et al., 2004; VIEIRA e GANDOLFI, 2006). Em estudos de fragmentos florestais em estágios iniciais de sucessão esta espécie apresentou valores de VI próximos ou bem menores do que o encontrado neste estudo (LOUZADA, 2002; SILVA JÚNIOR, 2002; SILVA, 2002; BRAGA, 2010). Porém, em florestas maduras esta espécie tende a apresentar maiores valores de VI. Braga (2010) verificou que esta espécie apresentava o terceiro maior VI (5,58\%) em floresta avançada em termos sucessionais na Zona da Mata Mineira. A inclusão desta espécie em programas de restauração florestal ou em plantios de enriquecimento pode contribuir para aumentar o aporte dos fragmentos florestais para estocar carbono.

Das seis espécies mais representativas do fragmento florestal para as quatro variáveis relativas (dominância, frequência, densidade e estocagem de carbono) apenas Croton urucurana e Guettarda viburnoides apresentaram mudança positiva de posição no ranking de espécies de maior valor de importância (Tabela 1 e Figura 1). Croton urucurana subiu quatro posições no ranking, devido a sua elevada densidade básica da madeira $\left(0,83 \mathrm{~g} / \mathrm{cm}^{3}\right)$, apresentando boa capacidade de estocar carbono aliado ao alto valor de importância desta espécie na área de estudo. Croton urucurana é uma espécie pioneira característica de terrenos muito úmidos e brejosos (LORENZI, 2002), sendo indicada para plantios mistos em áreas ciliares degradadas (LUCHI, 2004). Esta espécie esteve presente em diversos estudos ecológicos em Floresta Estacional Semidecidual, principalmente em fragmentos em estágio inicial de sucessão (FREITAS, 2001; LOUZADA, 2002; BRAGA, 2010). O potencial apresentado para estocar carbono agrega ainda mais valor para que esta espécie seja utilizada em programas de restauração florestal.

Pode-se observar que a utilização da variável carbono influenciou sobremaneira o valor de importância das espécies. Esta metodologia serve como suporte para a escolha de espécies arbóreas de maior potencial para sequestrar carbono e pode subsidiar programas de restauração de remanescentes florestais do Bioma de Mata Atlântica.

A média de estoque de carbono encontrado na biomassa da parte aérea foi de 58,3 tha ${ }^{-1}$. Estes valores são intermediários aos valores encontrados em outros estudos com o mesmo nível de inclusão das árvores em florestas de Mata Atlântica. Melo e Durigan (2006), em uma área de Floresta Estacional Semidecidual, localizada em mata ciliar natural madura no estado de São Paulo, encontraram uma estimativa de 80 t.ha $^{-1}$ de carbono. Ferez (2010) encontrou um estoque de 138 t.ha ${ }^{-1}$ para uma área de Floresta Mesófila Semidecidual, também no estado de São Paulo. Valores inferiores também foram encontrados em estudo de quantificação de carbono. Ribeiro et al. (2010) encontraram um estoque de 20 t.ha $^{-1}$ de carbono em uma capoeira de Floresta Estacional Semidecidual Montana no Estado de Minas Gerais. Tiepolo et al. (2002) estimaram valores de 42,89 t.ha-1 de carbono em uma floresta secundária jovem em uma reserva no estado do Paraná.

Apesar do mesmo nível de inclusão adotado nestas comparações, as variações encontradas podem estar associadas a diversos fatores. Mesmo sendo pertencentes ao Bioma Mata Atlântica, o estágio sucessional que as florestas se encontravam influenciam diretamente nos valores de estocagem de carbono. Além disso, a metodologia adotada em cada trabalho pode ter influenciado os resultados, como por exemplo, a desconsideração da densidade básica da madeira para cada espécie, que neste estudo variou de 0,39 a $1,19\left(\mathrm{~g} / \mathrm{cm}^{3}\right)$.

Os resultados indicam que o estoque de carbono encontrado equivale a fragmentos em estágio médio de sucessão (BOINA, 2008).

\section{CONCLUSÕES}

A inclusão da variável estoque de carbono na estrutura horizontal da análise fitossociológica resultou em mudanças na ordem de valor de importância das espécies, contribuindo para a identificação das espécies com maior potencial para sequestrar carbono.

A capacidade de estocar carbono deve ser considerada como fator importante na escolha de espécies a serem utilizadas em programas de restauração florestal, visando aumentar o potencial dos fragmentos florestais de retirar e estocar carbono da atmosfera.

\section{REFERÊNCIAS BIBLIOGRÁFICAS}

AMARO, M. A. Quantificação do estoque 
volumétrico, de biomassa e de carbono em uma floresta estacional semidecidual no município de Viçosa-MG Viçosa, 2010, 168 f. Tese (Doutorado em Ciência Florestal) - Universidade Federal de Viçosa, 2010.

BOINA, A. Quantificação de estoques de biomassa e de carbono em floresta estacional semidecidual, vale do rio doce, Minas Gerais. Viçosa, 2008, 89 f. Dissertação (Mestrado em Ciência Florestal) Universidade Federal de Viçosa, 2008.

BORÉM, R. A. T.; OLIVEIRA-FILHO, A. T. Fitossociologia do estrato arbóreo em uma toposeqüência alternada de mata atlântica, no munícipio de Silva Jardim - RJ, Brasil. Revista Árvore, v. 26, n. 6, p. 727-742, 2002.

BRAGA, A. J. T. Estudos ecológicos em floresta estacional semidecidual, Viçosa - MG. Viçosa, 2010, 115 f. Dissertação (Doutorado em Ciência Florestal) - Universidade Federal de Viçosa, 2010.

BRAGA, A. J. T. et al. Composição do banco de sementes de uma floresta semidecidual secundária considerando o seu potencial de uso para recuperação ambiental. Revista Árvore, v. 32, n. 6, p. 1089-1098, 2008.

BRASIL. Resolução/CONAMA No $\mathrm{N}^{\circ} 392$, de 25 de junho de 2007. Define vegetação primária e secundária de regeneração de Mata Atlântica no Estado de Minas Gerais. Diário Oficial da República Federativa do Brasil. Brasília-DF, 26 de junho de 2007.

CARVALHO, P. E. R. Espécies arbóreas brasileiras. Brasília, DF: Embrapa Informação Tecnológica; Colombo: Embrapa Florestas, 2003. $1039 \mathrm{p}$.

CARVALHO, F. A. et al. Estrutura e composição florística do estrato arbóreo de um remanescente de mata atlântica submontana no município de Rio Bonito, RJ, Brasil (Mata Rio Vermelho). Revista Árvore, v. 31, n. 4, p.717-730, 2007.

CHAZDON, R. L. Beyond deforestation: restoring forests and ecosystem services on degraded lands. Science, v. 320, p. 1458-1460, 2008.

COPAM - Conselho de Política Ambiental. 1997. Lista das espécies ameaçadas de extinção da flora do Estado de Minas Gerais. Deliberação COPAM 85/97.

CUNHA, G. M. et al. Biomassa e estoque de carbono e nutrientes em florestas montanas da mata atlântica na região norte do estado do Rio de Janeiro. Revista Brasileira de Ciência do Solo, v. 33, p. 1175-1185, 2009.

DURIGAN, G.; MELO, A. C. G. Fixação de carbono em reflorestamentos de matas ciliares no Vale do Paranapanema, SP, Brasil. Scientia Forestalis, v. 71, p.149-154, 2006.

FANG, J.; CHEN, A.; PENG, C.; ZHAO, S.; CI, L. Changes in forest biomass carbon storage in China between 1949 and 1998. Science, v. 292, n. 5.525, p. 2.320-2.322, 2001.

FEARNSIDE, P. Desmatamento na Amazônia: dinâmica, impactos e controle. Acta Amazônica, v. 36, n. 3, p. 395-400, 2006.

FEREZ, A. P. C. Efeito de práticas silviculturais sobre as taxas iniciais de sequiestro de carbono em plantios de restauração da mata atlântica. 2010, 104 f. Dissertação (Mestrado em Ciências) - Escola Superior de Agricltura "Luiz de Queiroz", Piracicaba, 2010.

FORSTER, H. W.; MELO, A. C. G. de. Biomassa aérea e de raízes em árvores de reflorestamentos heterogêneos no Vale do Paranapanema, SP. IF Série Registros, n. 31, p. 153-157, 2007.

FREITAS, L. J. M. Inventário de prospecção e otimização da colheita visando a sustentabilidade do manejo de uma floresta estacional semidecidual submontana. 2001, 78 f. Dissertação (Mestrado em Ciência Florestal) - Universidade Federal de Viçosa, Viçosa, 2001.

FUKUDA, M.; IEHARA, T.; MATSUMOTO, M. Carbon stock estimates for sugi and hinoki forests in Japan. Forest ecology and management, v. 184, n. 1-3, p. 1-16, 2003.

FUNDAÇÃO CENTRO TECNOLÓGICO DE MINAS GERAIS - CETEC. Determinação de equações volumétricas aplicáveis ao manejo sustentado de florestas nativas no estado de Minas Gerais e outras regiões do país. Belo Horizonte: SAT/CETEC, 1995. 295 p.

GASPAR, R. O. Dinâmica e crescimento do estrato arbóreo em áreas de mata atlântica, na região do Vale do Rio Doce, MG. 2008. 177 f. Dissertação (Mestrado em Ciência Florestal) - Universidade Federal de Viçosa, 2008.

HOUGHTON, R. A. Aboveground forest biomass and the global carbon balance. Global Change Biology, v. 11, p. 945-958, 2005.

HÜLLER, A. et al. Estrutura fitossociológica da vegetação arbórea do Parque Natural Municipal de Santo Ângelo, Santo Ângelo, RS. Ciência Florestal, v. 21, n. 4, p. 629-639, 2011.

IBGE - Instituto Brasileiro de Geografia e Estatística. Mapa de vegetação do Brasil, 2004. Disponível em: <(ftp://geoftp.ibge.gov.br/mapas/ tematicos/mapas_murais) $>$ Acesso em: 20 de junho 
de 2010.

KAGEYAMA, P. Y.; GANDARA, F. B. Dinâmica de populações de espécies arbóreas para o manejo e a conservação. In: SIMPÓSIO DE ECOSSISTEMAS DA COSTA BRASILEIRA (ACIESP), 3., 1993. Anais ... 1993.

KALIL FILHO, A. N. et al. Espécies recomendadas para a restauração da Mata Atlântica. In: GALVÃO, A. P. M.; MEDEIROS, A. C. S. (Ed.). Restauração da Mata Atlântica em áreas de sua primitiva ocorrência natural. Colombo: EMBRAPA Florestas, 2002. $134 \mathrm{p}$.

LAMB, D.; ERSKINE, P. D.; PARROTTA, J. A. Restoration of degraded tropical forest landscapes. Science, v. 310, p. 1628-1632, 2005.

LORENZI, H. Árvores brasileiras: manual de identificação e cultivo de plantas arbóreas nativas do Brasil. Nova Odessa: Plantarum, 2002. v. 1. 368 p.

LORENZI, H. Árvores brasileiras: manual de identificação e cultivo de plantas arbóreas nativas do Brasil. Nova Odessa: Plantarum, 2009a, v. 2, $384 \mathrm{p}$.

LORENZI, H. Árvores brasileiras: manual de identificação e cultivo de plantas arbóreas nativas do Brasil. Nova Odessa: Plantarum, 2009b, v. 3, $384 \mathrm{p}$.

LOUZADA, C. Composição florística e estrutura de vegetação arbórea em diferentes condições fisiográficas de um fragmento de floresta estacional semidecidual secundária, na Zona da Mata de Minas Gerais. 2002. 149 f. Dissertação (Mestrado em Ciência Florestal) - Universidade Federal de Viçosa, Viçosa, 2002.

LUCHI, A. E. Anatomia do lenho de Croton urucurana Baill. (Euphorbiaceae) de solos com diferentes níveis de umidade. Revista Brasileira de Botânica, v. 27, n. 2, p. 271-280, 2004.

MARANGON, L. C.; SOARES, J. J.; FELICIANO, A. L. P. Florística arbórea da Mata da Pedreira, município de Viçosa, Minas Gerais. Revista Árvore, v. 27, n. 2, p. 207-215, 2003.

MARTINS, F. R. O método de quadrantes e a fitossociologia de uma floresta residual do interior do estado de São Paulo: Parque Estadual de Vassununga. 1979. 239 f. Tese (Doutorado) Instituto de Biociências, Universidade de São Paulo, São Paulo. 1979.

MELO,A. C. G.; DURIGAN, G. Fixação de carbono em reflorestamentos de matas ciliares no Vale do Paranapanema, SP, Brasil. Scientia Forestalis, v. 71, p. 149-154, 2006.

MEYER, S. T. et al. Composição florística da vegetação arbórea de um trecho de floresta de galeria do Parque Estadual do Rola-Moça na Região Metropolitana de Belo Horizonte, MG, Brasil. Acta Botanica Brasileira, v. 18, n. 4, p. 701-709, 2004. MONTAGNINI, F.; PORRAS, C. Evaluating the role of plantations as carbon sinks: An example of an integrative approach from the humid tropics. Environmental Management, v. 22, p. 459-470, 1998.

MORELLATO, L. P.; HADDAD, C. F. B. Introduction: the Brazilian Atlantic Forest. Biotropica, v. 32, p. 786-792, 2000.

NÓBREGA, A. M. F. et al. Uso da fitossociologia na avaliação da efetividade da restauração florestal em uma várzea degradada do rio Mogi Guaçu, SP.

Scientia Forestalis, n. 75, p. 51-63, 2007.

PÉREZ, J. F. M. Sistema de manejo para a candeia (E. erythropappus (DC.) McLeish). 2001, 71 f. Dissertação (Mestrado em Engenharia Florestal) Universidade Federal de Lavras, Lavras, 2001.

PINTO, S. I. C. et al. Estrutura do componente arbustivo-arbóreo de dois estádios sucessionais de floresta estacional semidecidual na reserva florestal mata do paraíso, Viçosa, MG, Brasil. Revista Árvore, v. 31, n. 5, p. 823-833, 2007.

RIBAS, R. F. et al. Composição florística de dois trechos em diferentes etapas serais de uma floresta estacional semidecidual em Viçosa, Minas Gerais. Revista Árvore, v. 27, n. 6, p. 821-830, 2003.

RIBEIRO, M. C. et al. Brazilian Atlantic forest: how much is left and how is the remaining forest distributed? Implications for conservation. Biological Conservation, v. 142, p. 1141-1153, 2009.

RIBEIRO, S. C. et al. Quantificação de biomassa e estimativa de estoque de carbono em uma capoeira da Zona da Mata Mineira. Revista Árvore, v. 34, p. 495-504, 2010.

RIZZINI, C. T. Árvores e madeiras úteis do Brasil: manual de dendrologia brasileira. São Paulo: E. Edgard Blücher, 1979. 296 p.

SIF - Sociedade de Investigações Florestais, Universidade Federal de Viçosa - UFV. Estudos florísticos e fitossociológicos em áreas de reserva legal e preservação permanente da CENIBRA S.A., 2003. 127 p.

SILVA JUNIOR, W. M. Caracterização florística e fitossociológica da regeneração natural em dois trechos de uma floresta Estacional semidecidual no município de Viçosa, MG. 2002. 76 f. Dissertação (Mestrado em Ciência Florestal) - Universidade Federal de Viçosa, Viçosa, 
2002.

SILVA, A. F. et al. Composição florística e estrutura horizontal do estrato arbóreo de um trecho da mata da biologia da Universidade Federal de Viçosa Zona da Mata de Minas Gerais. Revista Árvore, v. 24, n. 4, p. 397-405, 2000.

SILVA, A. C. et al. Relações florísticas e fitossociologia de uma Floresta Ambófila Mista Montana em Lages, Santa Catarina. Ciência Florestal, v. 22, n. 1, p. 193-206, 2012.

SILVA, C. T. et al. Avaliação temporal da florística arbórea de uma floresta secundária no município de Viçosa, Minas Gerais. Revista Árvore, v. 28, n. 3 , p. 429-441, 2004.

SILVA, N. R. S. Florística e estrutura horizontal de uma floresta estacional semidecidual montana - mata do Juquinha de Paula, Viçosa, MG. 2002. 68f. Dissertação (Mestrado em Ciência Florestal) - Universidade Federal de Viçosa, Viçosa, 2002.

SILVER, W. L.; OSTERTAG, R.; LUGO, A. E. The potential for carbon sequestration through reforestation of abandoned tropical pastural and agricultural lands. Restoration Ecology, v. 8, p. $394-407,2000$.

SOARES, C. P. B.; NETO, F. P.; SOUZA, A. L. Dendrometria e Inventário Florestal. 2. ed. Viçosa: Ed. da UFV. 2011. 272 p.
SOARES, C. P. B.; OLIVEIRA, M. L. R. Equações para estimar a quantidade de carbono na parte aérea de árvores de eucalipto em Viçosa, Minas Gerais. Revista Árvore, v. 26, n. 5, p. 533-539, 2002.

TABARELLI, M. et al. Challenges and opportunities for biodiversity conservation in the Brazilian Atlantic forest. Conservation Biology, v. 19, p. 695-700, 2005.

TIEPOLO, G.; CALMON, M.; FERETTI, A. R. Measuring and monitoring carbon stocks at the Guaraqueçaba climate action project, Paraná, Brazil. In: INTERNATIONAL SYMPOSIUM ON FOREST CARBON SEQUESTRATION AND MONITORING, 2002, Taipei, Taiwan. Anais... Taipei: Taiwan Forestry Research Institute, 2002. p. 98-115.

VELOSO, H. P.; RANGEL FILHO, A. L. R.; LIMA, J. C. A. Classificação da vegetação brasileira, adaptada a um sistema universal. Rio de Janeiro: Instituto Brasileiro de Geografia e Estatística (IBGE), 1991. $123 \mathrm{p}$.

VIEIRA, D. C. M.; GANDOLFI, S. Chuva de sementes e regenerarão em uma área restaurada. Revista Brasileira de Botânica, v. 29, n. 4, p. 541-554, 2006.

YOUNG, T. P. Restoration ecology and conservation biology. Biological Conservation, v. 92, p. 73-83, 2000. 